\title{
Arsenic trioxide-based therapy in relapsed/ refractory multiple myeloma patients: a meta-analysis and systematic review
}

This article was published in the following Dove Press journal:

OncoTargets and Therapy

10 September 2014

Number of times this article has been viewed

\author{
Xuepeng $\mathrm{He}$ \\ Kai Yang \\ Peng Chen \\ Bing Liu \\ Yuan Zhang \\ Fang Wang \\ Zhi Guo \\ Xiaodong Liu \\ Jinxing Lou \\ Huiren Chen \\ Department of Hematology, \\ General Hospital of Beijing \\ Military Area of PLA, Beijing, \\ People's Republic of China
}

Correspondence: Xuepeng $\mathrm{He}$ Department of Hematology, General Hospital of Beijing Military Area of PLA, Beijing 100700,

People's Republic of China

Tel +8601084008139

Email xuepenghemd@gmail.com

\begin{abstract}
Multiple myeloma (MM) is a clonal malignancy characterized by the proliferation of malignant plasma cells in the bone marrow and the production of monoclonal immunoglobulin. Although some newly approved drugs (thalidomide, lenalidomide, and bortezomib) demonstrate significant benefit for MM patients with improved survival, all MM patients still relapse. Arsenic trioxide (ATO) is the most active single agent in acute promyelocytic leukemia, the antitumor activity of which is partly dependent on the production of reactive oxygen species. Due to its multifaceted effects observed on MM cell lines and primary myeloma cells, Phase I/II trials have been conducted in heavily pretreated patients with relapsed or refractory MM. Therapy regimens varied dramatically as to the dosage of ATO and monotherapy versus combination therapy with other agents available for the treatment of MM. Although ATO-based combination treatment was well tolerated by most patients, most trials found that ATO has limited effects on MM patients. However, since small numbers of patients were randomized to different treatment arms, trials have not been statistically powered to determine the differences in progression-free survival and overall survival among the experimental arms. Therefore, large Phase III studies of ATO-based randomized controlled trials will be needed to establish whether ATO has any potential beneficial effects in the clinical setting.
\end{abstract}

Keywords: multiple myeloma, arsenic trioxide, clinical trial, therapy, meta-analysis

\section{Introduction}

Multiple myeloma (MM) is a clonal malignancy characterized by the proliferation of malignant plasma cells in the bone marrow and the production of monoclonal immunoglobulin. ${ }^{1} \mathrm{MM}$, which is the most common primary tumor of the bone marrow, is an incurable tumor that occurs in 4.8 to eight per 1,000,000 in the US. It is estimated that 21,700 people in the US have suffered from MM, and deaths from the year 2012 numbered 6,020 people. ${ }^{2}$ The majority of MM patients will relapse or become refractory to therapy after achieving complete remission. ${ }^{3}$ Over the past decade, treatment for MM patients has been greatly improved due to autologous stem cell transplantation and new drugs (thalidomide, lenalidomide, and bortezomib). These management increased rate of complete response (CR) and subsequently extended survival both in young and elderly patients with MM. ${ }^{3}$ MM patients usually achieved CR more quickly by using the new drugs, which was associated with longer survival. However, most patients eventually relapse after $\mathrm{CR}$, indicating that residual tumor cells exist. Resistance to conventional therapy caused by residual diseases displays multifactorial characteristics, which are difficult to overcome by targeting one single mechanism. ${ }^{4}$ Alternatively, identification of novel cellular targets or signaling pathways regulating myeloma cell 
growth would improve clinical outcome and survival in MM patients refractory to chemotherapy. Mitochondria, which have been implied to play a crucial role in programmed cell death, apoptosis, are found to be a promising drug target that may benefit MM patients or other tumor patients. ${ }^{5-7}$

Arsenic trioxide (ATO) is the most active single agent used in the treatment of acute promyelocytic leukemia (APL) patients (newly diagnosed and relapsed or refractory APL patients). ${ }^{8,9}$ The rationale for ATO as a therapy for MM is that ATO inhibits cell viability, suppresses growth, and induces apoptosis in myeloma cells in an in vitro cell culture model. ${ }^{10,11}$ Instead of affecting the extrinsic (receptor-mediated) apoptotic pathway, ATO was proposed to disrupt the intrinsic (mitochondria-mediated) apoptosis pathways by generating reactive oxygen species (ROS) and suppressing the reduced glutathione (GSH) cellular redox enzymes, GSH peroxidase and thiotransferase (glutaredoxin). ${ }^{1,4}$ Due to multifaceted effects of ATO on MM cell lines and primary myeloma cells, Phase I/II trials have been conducted in relapsed or refractory MM patients with heavy pretreatment. However, the application of ATO has so far achieved limited success in relapsed/refractory $\mathrm{MM},{ }^{12}$ which could be attributed to the acquisition of resistance in $\mathrm{MM}$ due to changes in $\mathrm{GSH}$ levels and apoptotic regulators or other unknown reasons. ${ }^{12}$ In this study, we will review and update the published clinical studies as to the effect of ATO on MM in adults.

\section{Methods}

\section{Search strategy and selection criteria}

MEDLINE, PubMed, and Web of Science were searched in December 2013 using the search terms "arsenic trioxide", "multiple myeloma", and "clinical studies" and synonymous search terms such as "arsenite", "chemical LAND21", "myeloma", and "clinical trials". Studies identified through the approach as described were screened by titles first, then by abstracts of the publications. After exclusion of nonrelevant publications and identification of duplicates from the different databases, the remaining papers were evaluated in the full-text version for inclusion and exclusion criteria and for relevant articles in the reference lists. All clinical studies except case reports were chosen: eg, randomized controlled trials (RCTs), cohort studies, case control studies, and case series. The language of publication was restricted to English and Chinese. Only the studies containing 15 or more patients were eligible for inclusion. All searched data were retrieved. Authors' bibliographies and references of selected studies were also searched for other relevant studies. The most complete study was chosen to avoid duplication if same patient populations were reported in several publications.
Adult patients with progressive MM who were shown to have chemoresistant relapse and/or refractory MM were eligible for the study. The response of patients with MM to chemotherapy was determined according to criteria raised by Blade et al. ${ }^{13}$ Briefly, CR was defined as negative myeloma protein in serum and in urine on at least two determinations for a minimum of 6 weeks, no increase in the size of lytic bone lesions, and $<5 \%$ plasma cells in the marrow. Partial response $(\mathrm{PR})$ was defined as a $\geq 50 \%$ reduction in the level of serum M-protein on at least two determinations 6 weeks apart, reduction in 24-hour urinary light-chain excretion by either $\geq 90 \%$ or to $<0.2 \mathrm{~g}$ (if present), $\geq 50 \%$ reduction in size of soft tissue plasmacytomas, and no increase in size or number of lytic bone lesions. Minor response (MR) was defined as $25 \%-49 \%$ reduction in serum M-protein, 50\%-89\% reduction in urine M-protein (if present), 25\%-49\% reduction in size of plasmacytomas, and no increase in size or number of lytic bone lesions. Progressive disease (PD) was defined as $>25 \%$ increase in serum M-protein or in 24-hour urinary light-chain excretion, an increase in size or development of new existing lytic bone lesions, or plasmacytomas or development of hypercalcemia. CR, PR, and MR were considered responses to the treatment in terms of treatment effectiveness. All publications regarding in vitro/ex vivo studies, cell lines, and human xenografts were excluded. There were no restrictions on the types of interventions of ATO-containing therapy regimens, either as a single drug or in combination with other agents. Overall response rates (CR, PR, and MR) and probabilities for overall survival (OS) and progressionfree survival (PFS), where applicable, will be included.

Data for study characteristics and clinical response were summarized and incorporated into table format. Heterogeneity of investigation was evaluated to determine whether the data of the various studies could be analyzed in a meta-analysis.

The database search generated 36 articles from PubMed and two from the Web of Science. After initial screening of all titles, abstracts, and eligibility, ten full-text studies were selected for more detailed assessment. A search of the article references did not produce additional publications. Eventually, ten publications met the inclusion criteria for qualitative study and two for meta-analysis. The article search and study selection are depicted in Figure 1.

\section{Results \\ Response to, and efficacy of, ATO-based therapy}

Eight of ten included intervention studies were designed as case series, and two studies applied ATO in an RCT setting. 


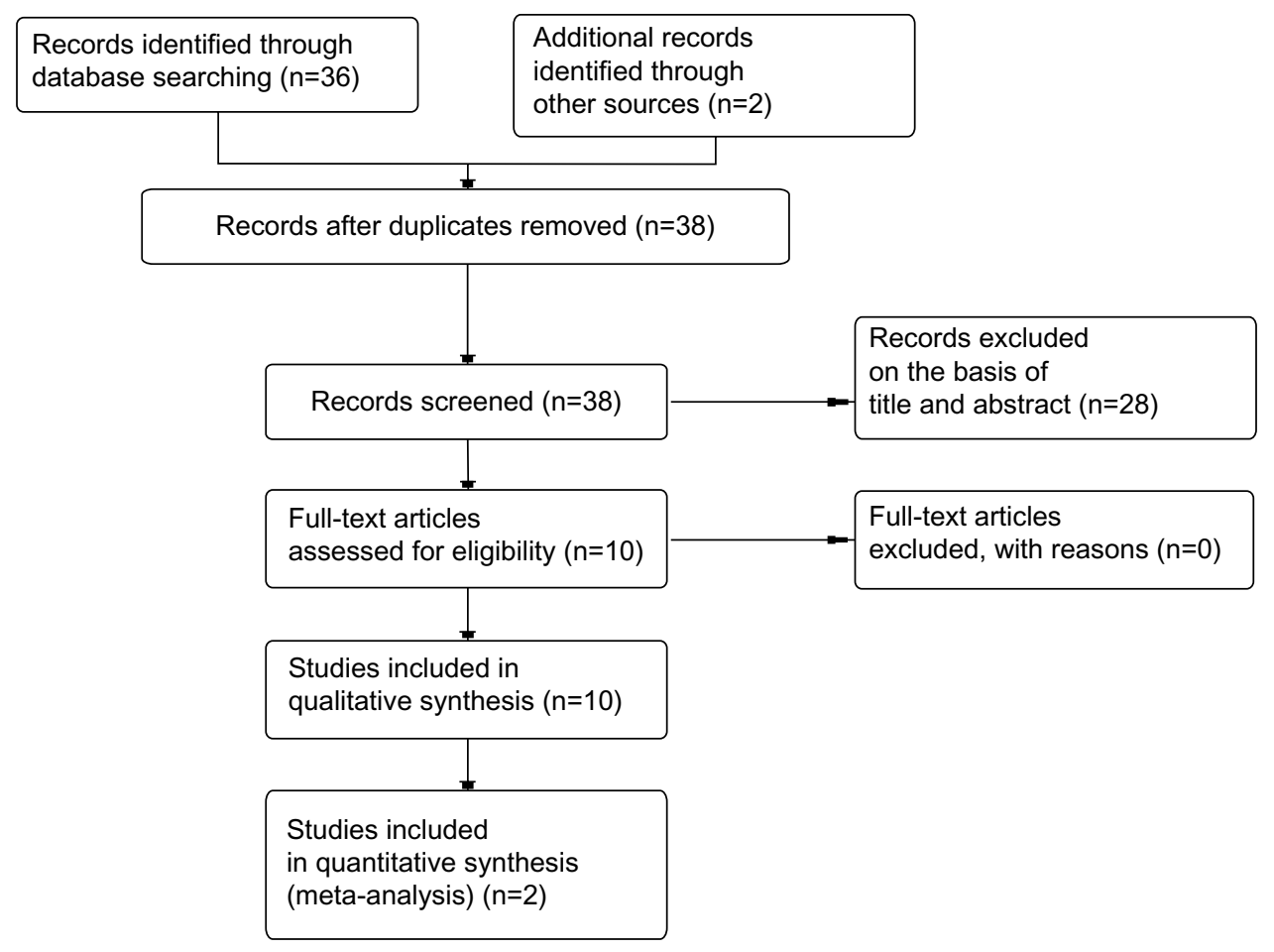

Figure I Flow chart of study selection.

All the trials recruited patients who suffered from progressive MM, defined as being either refractory to conventional therapy or in a relapsed state. The median age was from 50.8 years to 66 years. The number of patients ranged from 15 to 65 . Studies containing fewer than 15 patients were excluded. ${ }^{14-22}$ All studies were published between 2003 and 2012 and performed in both developing and developed countries. Therapy regimens varied dramatically as to the dosage of ATO and monotherapy/combinations with other agents available for the treatment of MM. ATO dosage varied from $0.125 \mathrm{mg} / \mathrm{kg} /$ day to $0.3 \mathrm{mg} / \mathrm{kg} /$ day. Only one study utilized ATO as monotherapy. ${ }^{23}$ Other drugs utilized in combination regimens were ascorbic acid (AA), melphalan, dexamethasone, bortezomib, thalidomide, and doxorubicin. All ten studies utilized changes in the serum monoclonal protein levels to determine the response reaction $(\mathrm{CR}, \mathrm{PR}$, stable disease, and PD). Four investigations retrieved information as to the probability of OS and PFS. ${ }^{24-27}$ Detailed features of the studies are described in Table 1. Two of the included studies with 77 patients investigated the association between ATO treatment and response to ATO-based therapy. A random effects model was chosen for analysis because of heterogeneity. The combined OR was 0.64 (95\% confidence interval: $0.17-2.35 ; Z=0.68 ; P=0.5$ ) (Figure 2), indicating that ATO treatment was not correlated with CR or PR in patients with advanced MM.

\section{Safety and tolerability}

All patients were evaluable for safety and tolerability. ATO-based combination therapy was well tolerated by most patients, but several significant toxicity events in heavily pretreated patients have been reported. ${ }^{28}$ The adverse effects and their frequencies are listed in Table 2.

\section{Discussion}

ATO, a beneficial antineoplastic drug for $\mathrm{MM}^{29}$ has been identified to exert effects on myeloma cells through different molecular mechanisms. ${ }^{30}$ Instead of inducing differentiation of myeloma cells as it did in APL, ${ }^{8,9}$ ATO induces apoptosis and inhibits proliferation and angiogenesis in MM cells via various signaling pathways. First, ATO induces apoptosis by generation of $\operatorname{ROS}^{31,32}$ and reduction of free GSH. ${ }^{26}$ In contrast to triggering proapoptotic signaling pathways upstream of mitochondria, ATO acts directly on mitochondria to generate apoptosis. ${ }^{4,33}$ ATO-associated combination of activation in ROS and inhibition in the GSH cellular redox systems seems to directly disrupt mitochondrial membrane potential and damage mitochondria of susceptible myeloma cells. ${ }^{4,26}$ Second, in myeloma cells, constitutive STAT3 activation and upregulation of $\mathrm{BCL}-\mathrm{xL}$ confer resistance to apoptosis and generate multidrug-resistant phenotype. ${ }^{34,35}$ ATO inhibits interleukin-6-mediated phosphorylation of STAT3 and blocks early activation of JAK1 and JAK2 in 


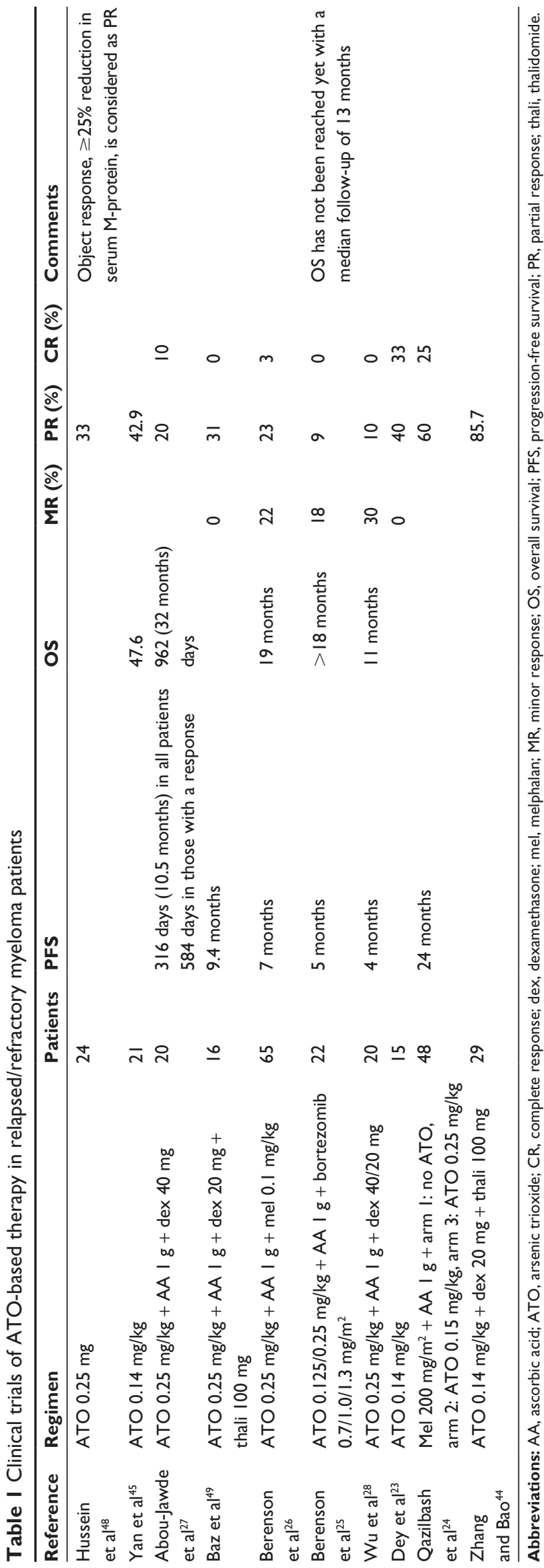

the JAK/STAT3 pathway, known to promote cell survival. ${ }^{36}$ Additionally, ATO activates JNK pathway in ATO-sensitive myeloma cells but not in ATO-insensitive/resistant myeloma cells, which might improve outcome in MM therapy. ${ }^{37} \mathrm{In}$ contrast, ATO activates the p38/MAPK pathway that contributes to resistance to ATO in myeloma cells. ${ }^{38,39}$ Inhibition of NF- $\kappa B$ activation by ATO was observed to react with a critical cystein in the activation loop of IKB kinase. ${ }^{40}$ Finally, ATO may also block vascular endothelial growth factor-mediated migration of myeloma cells and bone marrow neovascularization induced by NF-KB. ${ }^{41}$ However, the ERK/MAPK and AKT pathways activated in myeloma cells are not affected by ATO. ${ }^{42,43}$ ATO did not affect expression of BCL-xL either. ${ }^{43}$

The response of patients with MM to chemotherapy was determined according to criteria raised by Blade et al. ${ }^{13}$ The results of the studies on effects and toxicities of ATO on MM patients were not consistent from different research groups. Most clinical trials found that ATO has limited effects on MM patients because of severe toxicity and less efficacy compared with other newly found drugs. ATO therapy, combined with AA and dexamethasone, causes significant toxicity in relapsed and/or refractory MM patients with heavy pretreatment, while the effects of ATO-based regimens are inferior to other new medication-based combination therapy such as bortezomib and thalidomide.$^{28}$ Although the results from the combination therapy with ATO, AA, and bortezomib in advanced MM patients are encouraging, MM patients fail to obtain significant benefit from ATO-involved combination therapy compared with that produced by monotherapy using a single drug. ${ }^{25}$ In contrast, Zhang and $\mathrm{Bao}^{44}$ reported that therapy with ATO, dexamethasone, and thalidomide causes minor toxicity in patients with relapsed and/or refractory MM, suggesting that ATO-based combination therapy is effective and safe for advanced MM patients.

Data variations among the studies, such as variation in dosage, treatment duration, make it incredibly difficult to conduct a quantitative analysis. Therefore, most results were described as narrative data. Two RCTs were eligible to be analyzed in a meta-analysis format (Figure 2).

In Table 1, we list ten examples of literature in the past 10 years with number of patients larger than 15 . By comparing with the review by Rollig and Illmer, ${ }^{1}$ we added two more recent publications, Zhang and $\mathrm{Bao}^{44}$ and Yan et al. ${ }^{45} \mathrm{We}$ did not include literature containing fewer than 15 patients: eg, Hofmeister et a ${ }^{14}$ and Borad et al. ${ }^{17} \mathrm{~A}$ clinical trial conducted in Iran in $2011^{22}$ only had 12 MM patients, which did not reach our criterion of 15 , so we removed this publication from 
+ATO $\quad$-ATO Odds ratio Odds ratio

Study or subgroup Events Total Events Total Weight $\mathrm{M}-\mathrm{H}$, fixed, $95 \% \mathrm{Cl} \quad \mathrm{M}-\mathrm{H}$, fixed, $95 \% \mathrm{Cl}$

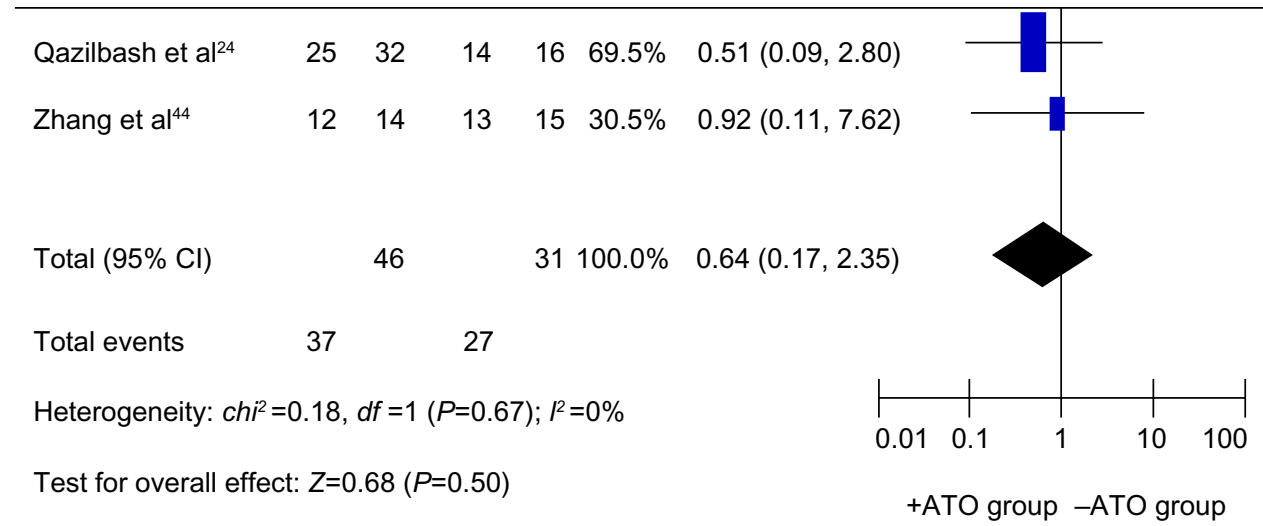

Figure 2 Forest plot showing the correlation between ATO application and clinical response to ATO-based therapy in advanced MM.

Notes: Two of these included studies with 77 multiple myeloma (MM) patients investigated the association between arsenic trioxide (ATO) treatment and response to ATObased therapy. A random effects model was chosen for analysis because of heterogeneity. The combined odds ratio was 0.64 ( $95 \%$ confidence interval [Cl]: $0.17-2.35 ; Z=0.68$; $P=0.5)$.

our review. A randomized Phase II trial ${ }^{46}$ was also excluded because it focused on 58 patients to determine whether adding bortezomib to a preparative regimen of ATO, AA, and high-dose melphalan was safe.

One of the antitumor activities of ATO is due to the production of ROS. Not surprisingly, AA, which accentuates ROS, has been shown to enhance anti-MM effects in MM patients. ${ }^{15}$ However, other studies discovered that AA may inhibit antitumor effects induced by ATO.$^{25,47}$ At present, there is no explanation for the discrepancy between studies from different groups. Therefore, large Phase III studies will be necessary to decipher effects of AA on ATO in the clinical setting. In one of the RCTs,${ }^{24} 16$ of the 19 patients with advanced MM were randomized to ATO-based groups, and their PFS and OS were comparable with patients in the control group. Since the small number of patients (48 patients) was randomized to three different treatment arms, the small number of patients is not statistically powered to determine the differences in PFS and OS among the three experimental arms. Therefore, large Phase III studies of ATO-based RCTs will be needed to analyze whether ATO has any potential beneficial effects in the clinical setting.

Because of the relatively low incidence of $\mathrm{MM}$, it is difficult to obtain a large number of patients in each clinical trial. Over the past decades, the numbers of the patients in a variety of trials vary from four to 65 . Only two studies performed in 2008 and 2012 are qualified for quantitative meta-analysis. Actually, there is no fixed minimum number of studies required for meta-analysis, although the resulting effect size can be unstable due to a small number of studies. However, our meta-analyse obtains consistent conclusions compared with previous studies. Therefore, the analyzed data

Table 2 Adverse effects of arsenic trioxide-based therapy in relapsed/refractory myeloma patients

\begin{tabular}{|c|c|c|c|c|c|c|c|c|c|}
\hline \multirow[t]{2}{*}{ Reference } & \multicolumn{3}{|c|}{ Hematological (\%) } & \multicolumn{6}{|c|}{ Nonhematological (\%) } \\
\hline & Anemia & Neutropenia & Thrombocytopenia & Cardiac & $\begin{array}{l}\text { Gastrointestinal } \\
\text { (diarrhea, vomiting, } \\
\text { stomatitis) }\end{array}$ & Hepatic & Renal & $\begin{array}{l}\text { Skin } \\
\text { rash }\end{array}$ & $\begin{array}{l}\text { Feverl } \\
\text { infections }\end{array}$ \\
\hline Hussein et $\mathrm{al}^{48}$ & 9 & 17 & & & 79 & 25 & & & 33 \\
\hline Yan et $a^{50}$ & & 5 & & 5 & & 19 & 5 & & \\
\hline Abou-Jawde & & 5 & & & & & & & \\
\hline \multicolumn{10}{|l|}{ et $\mathrm{al}^{27}$} \\
\hline \multicolumn{10}{|l|}{ Baz et $\mathrm{al}^{49}$} \\
\hline Berenson et $\mathrm{al}^{26}$ & 5 & 2 & & 6 & 6 & 2 & 2 & & 22 \\
\hline Berenson et $\mathrm{al}^{25}$ & & & 5 & 15 & & & & & 14 \\
\hline Wu et $\mathrm{al}^{28}$ & & 20 & 10 & & & 15 & & & 50 \\
\hline \multicolumn{10}{|l|}{ Dey et $\mathrm{al}^{23}$} \\
\hline Qazilbash et al $^{24}$ & & & & 6 & 52 & 2 & 6 & 4 & 23 \\
\hline Zhang and $\mathrm{Bao}^{44}$ & & & & & & & & & \\
\hline
\end{tabular}


are meaningful and acceptable. Another purpose of our review is to draw to the attention of the researchers that a larger Phase III trial is urgently needed to obtain more solid data to accept or reject the present conclusions for ATO in MM patients.

\section{Disclosure}

The authors have declared that no competing interests exist in this work.

\section{References}

1. Rollig C, Illmer T. The efficacy of arsenic trioxide for the treatment of relapsed and refractory multiple myeloma: a systematic review. Cancer Treat Rev. 2009;35:425-430.

2. Siegel R, Naishadham D, Jemal A. Cancer statistics, 2012. CA Cancer J Clin. 2012;62:10-29.

3. Genadieva-Stavric S, Cavallo F, Palumbo A. New approaches to management of multiple myeloma. Curr Treat Options Oncol. 2014; 15(2):157-170.

4. Dalton WS. Targeting the mitochondria: an exciting new approach to myeloma therapy. Commentary re: Bahlis NJ, et al. Feasibility and correlates of arsenic trioxide combined with ascorbic acid-mediated depletion of intracellular glutathione for the treatment of relapsed/ refractory multiple myeloma. Clin Cancer Res. 2002;8:3658-3668.

5. Chen YC, Lin-Shiau SY, Lin JK. Involvement of reactive oxygen species and caspase 3 activation in arsenite-induced apoptosis. J Cell Physiol. 1998;177:324-333.

6. Cai X, Shen YL, Zhu Q, et al. Arsenic trioxide-induced apoptosis and differentiation are associated respectively with mitochondrial transmembrane potential collapse and retinoic acid signaling pathways in acute promyelocytic leukemia. Leukemia. 2000;14:262-270.

7. Jia P, Chen G, Huang X, et al. Arsenic trioxide induces multiple myeloma cell apoptosis via disruption of mitochondrial transmembrane potentials and activation of caspase-3. Chin Med J (Engl). 2001; 114:19-24.

8. Chen GQ, Shi XG, Tang W, et al. Use of arsenic trioxide (As2O3) in the treatment of acute promyelocytic leukemia (APL): I. As2O3 exerts dosedependent dual effects on APL cells. Blood. 1997;89:3345-3353.

9. Shen ZX, Chen GQ, Ni JH, et al. Use of arsenic trioxide (As2O3) in the treatment of acute promyelocytic leukemia (APL): II. Clinical efficacy and pharmacokinetics in relapsed patients. Blood. 1997;89:3354-3360.

10. Park WH, Seol JG, Kim ES, et al. Arsenic trioxide-mediated growth inhibition in MC/CAR myeloma cells via cell cycle arrest in association with induction of cyclin-dependent kinase inhibitor, p21, and apoptosis. Cancer Res. 2000;60:3065-3071.

11. Hideshima T, Chauhan D, Richardson P, et al. NF-kappa B as a therapeutic target in multiple myeloma. J Biol Chem. 2002;277:16639-16647.

12. Matulis SM, Morales AA, Yehiayan L, Lee KP, Cai Y, Boise LH. Alterations in glutathione levels and apoptotic regulators are associated with acquisition of arsenic trioxide resistance in multiple myeloma. PLoS One. 2012; 7:e52662.

13. Blade J, Samson D, Reece D, et al. Criteria for evaluating disease response and progression in patients with multiple myeloma treated by high-dose therapy and haemopoietic stem cell transplantation. Myeloma Subcommittee of the EBMT. European Group for Blood and Marrow Transplant. Br J Haematol. 1998;102:1115-1123.

14. Hofmeister CC, Jansak B, Denlinger N, Kraut EH, Benson DM, Farag SS. Phase II clinical trial of arsenic trioxide with liposomal doxorubicin, vincristine, and dexamethasone in newly diagnosed multiple myeloma. Leuk Res. 2008;32:1295-1298.

15. Bahlis NJ, McCafferty-Grad J, Jordan-McMurry I, et al. Feasibility and correlates of arsenic trioxide combined with ascorbic acid-mediated depletion of intracellular glutathione for the treatment of relapsed/ refractory multiple myeloma. Clin Cancer Res. 2002;8:3658-3668.
16. Berenson JR, Swift RA, Ferretti D, Purner MB. A prospective, open-label safety and efficacy study of combination treatment with melphalan, arsenic trioxide, and ascorbic acid in patients with relapsed or refractory multiple myeloma. Clin Lymphoma. 2004;5:130-134.

17. Borad MJ, Swift R, Berenson JR. Efficacy of melphalan, arsenic trioxide, and ascorbic acid combination therapy (MAC) in relapsed and refractory multiple myeloma. Leukemia. 2005;19:154-156.

18. Gesundheit B, Shapira MY, Resnick I, et al. Trisenox (arsenic trioxide) in the treatment for multiple myeloma after bone marrow transplantation. Blood. 2005;106:365B.

19. Munshi NC, Tricot G, Desikan R, et al. Clinical activity of arsenic trioxide for the treatment of multiple myeloma. Leukemia. 2002;16:1835-1837.

20. Rousselot P, Larghero J, Arnulf B, et al. A clinical and pharmacological study of arsenic trioxide in advanced multiple myeloma patients. Leukemia. 2004;18:1518-1521.

21. Held LA, Rizzieri D, Long GD, et al. A Phase I study of arsenic trioxide (Trisenox), ascorbic acid, and bortezomib (Velcade) combination therapy in patients with relapsed/refractory multiple myeloma. Cancer Invest. 2013;31:172-176.

22. Sanaat Z, Rezazadeh M, Gharamaleki JV, Ziae JE, Esfahani A. Arsenic trioxide in patients with refractory multiple myeloma: a prospective, phase II, single-arm study. Acta Med Iran. 2011;49:504-508.

23. Dey S, Gupta P, Chitalkar PG, Mukhopadhyay A. Arsenic trioxide for treatment of multiple myeloma. Ann Oncol. 2007;18:ix178-ix182.

24. Qazilbash MH, Saliba RM, Nieto Y, et al. Arsenic trioxide with ascorbic acid and high-dose melphalan: results of a phase II randomized trial. Biol Blood Marrow Transplant. 2008;14:1401-1407.

25. Berenson JR, Matous J, Swift RA, Mapes R, Morrison B, Yeh HS. A phase I/II study of arsenic trioxide/bortezomib/ascorbic acid combination therapy for the treatment of relapsed or refractory multiple myeloma. Clin Cancer Res. 2007;13:1762-1768.

26. Berenson JR, Boccia R, Siegel D, et al. Efficacy and safety of melphalan, arsenic trioxide and ascorbic acid combination therapy in patients with relapsed or refractory multiple myeloma: a prospective, multicentre, phase II, single-arm study. Br J Haematol. 2006;135:174-183.

27. Abou-Jawde RM, Reed J, Kelly M, et al. Efficacy and safety results with the combination therapy of arsenic trioxide, dexamethasone, and ascorbic acid in multiple myeloma patients: a phase 2 trial. Med Oncol. 2006;23:263-272.

28. Wu KL, Beksac M, van Droogenbroeck J, Amadori S, Zweegman S, Sonneveld P. Phase II multicenter study of arsenic trioxide, ascorbic acid and dexamethasone in patients with relapsed or refractory multiple myeloma. Haematologica. 2006;91:1722-1723.

29. Rebersek K, Zontar DM, Cernelč P, Podgornik H. Selective apoptosis of multiple myeloma cells in primary samples induced by arsenic trioxide. Hematology. 2014;19(6):346-351.

30. Yang D, Cao F, Ye X, et al. Arsenic trioxide inhibits the hedgehog pathway which is aberrantly activated in acute promyelocytic leukemia. Acta Haematol. 2013;130:260-267.

31. Qu H, Tong D, Zhang Y, Kang K, Chen L, Ren L. The synergistic antitumor activity of arsenic trioxide and vitamin K2 in HL-60 cells involves increased ROS generation and regulation of the ROS-dependent MAPK signaling pathway. Pharmazie. 2013;68:839-845.

32. Cheng Y, Xue J, Jiang H, et al. Neuroprotective effect of resveratrol on arsenic trioxide-induced oxidative stress in feline brain. Hum Exp Toxicol. 2013;33(7):737-747.

33. Marchetti P, Mortier L, Beauvillain V, Formstecher P. [Are mitochondria targets of anticancer drugs responsible for apoptosis?]. Ann Biol Clin (Paris). 2002;60:391-403. French.

34. Catlett-Falcone R, Landowski TH, Oshiro MM, et al. Constitutive activation of Stat3 signaling confers resistance to apoptosis in human U266 myeloma cells. Immunity. 1999;10:105-115.

35. Tu Y, Renner S, Xu F, et al. BCL-X expression in multiple myeloma: possible indicator of chemoresistance. Cancer Res. 1998;58:256-262.

36. Hallek M, Bergsagel PL, Anderson KC. Multiple myeloma: increasing evidence for a multistep transformation process. Blood. 1998;91: $3-21$. 
37. Kajiguchi T, Yamamoto K, Iida S, Ueda R, Emi N, Naoe T. Sustained activation of c-jun-N-terminal kinase plays a critical role in arsenic trioxide-induced cell apoptosis in multiple myeloma cell lines. Cancer Sci. 2006;97:540-545.

38. Wen J, Feng Y, Huang W, et al. Enhanced antimyeloma cytotoxicity by the combination of arsenic trioxide and bortezomib is further potentiated by p38 MAPK inhibition. Leuk Res. 2010;34:85-92.

39. Wen J, Cheng HY, Feng Y, et al. P38 MAPK inhibition enhancing ATOinduced cytotoxicity against multiple myeloma cells. Br J Haematol. 2008;140:169-180.

40. Kapahi P, Takahashi T, Natoli G, et al. Inhibition of NF-kappa B activation by arsenite through reaction with a critical cysteine in the activation loop of Ikappa B kinase. J Biol Chem. 2000;275: 36062-36066.

41. Podar K, Tai YT, Davies FE, et al. Vascular endothelial growth factor triggers signaling cascades mediating multiple myeloma cell growth and migration. Blood. 2001;98:428-435.

42. Hideshima T, Nakamura N, Chauhan D, Anderson KC. Biologic sequelae of interleukin-6 induced PI3-K/Akt signaling in multiple myeloma. Oncogene. 2001;20:5991-6000.

43. Hayashi T, Hideshima T, Akiyama M, et al. Arsenic trioxide inhibits growth of human multiple myeloma cells in the bone marrow microenvironment. Mol Cancer Ther. 2002;1:851-860.
44. Zhang WJL, Bao S. Arsenic trioxide-based treatment of relapsed and refractory multiple myeloma. Chinese Community Physician. 2012;14:124-125.

45. Yan JWB, Xue Z, Sun J, Song Z. Clinical efficiency of arsenic trioxide for the treatment of relapsed/refractory multiple myeloma. Journal of Clinical Hematology. 2004;17:207-208.

46. Sharma M, Khan $\mathrm{H}$, Thall PF, et al. A randomized phase 2 trial of a preparative regimen of bortezomib, high-dose melphalan, arsenic trioxide, and ascorbic acid. Cancer. 2012;118:2507-2515.

47. Karasavvas N, Carcamo JM, Stratis G, Golde DW. Vitamin C protects HL60 and U266 cells from arsenic toxicity. Blood. 2005;105: 4004-4012.

48. Hussein MA, Saleh M, Ravandi F, Mason J, Rifkin RM, Ellison R. Phase 2 study of arsenic trioxide in patients with relapsed or refractory multiple myeloma. Br J Haematol. 2004;125:470-476.

49. Baz RC, Kelly M, Reed J, et al. Phase II study of dexamethasone, ascorbic acid, thalidomide and arsenic trioxide (DATA) in high risk previously untreated (PU) and relapsed/refractory (RR) multiple myeloma (MM). J Clin Oncol. 2006;24:17535.
OncoTargets and Therapy

\section{Publish your work in this journal}

OncoTargets and Therapy is an international, peer-reviewed, open access journal focusing on the pathological basis of all cancers, potential targets for therapy and treatment protocols employed to improve the management of cancer patients. The journal also focuses on the impact of management programs and new therapeutic agents and protocols on

\section{Dovepress}

patient perspectives such as quality of life, adherence and satisfaction. The manuscript management system is completely online and includes a very quick and fair peer-review system, which is all easy to use. Visit http://www.dovepress.com/testimonials.php to read real quotes from published authors. 